\title{
As vozes e diálogos do novo cinema iraniano
}

\author{
Michele Aline Jeremias de La Cruz ${ }^{1}$ \\ Denize Araujo²
}

\begin{abstract}
Resumo
Pluralidade e hibridação poética são elementos imanentes à estética do cinema de arte produzido no Irã. As temáticas universais, a autorreflexividade e a forte presença do cerceamento do Islã moldaram, ao longo dos anos, uma nova forma de fazer cinema que os realizadores persas encontraram para expressar a realidade social do país. As vozes humanistas e realistas dialogam com a proposta do Neorrealismo Italiano, a autonomia criativa dos realizadores remete ao movimento inovador da Nouvelle Vague francesa e, em alguns aspectos, ao Terceiro Cinema. Neste artigo, pretendemos elucidar o controle do estado sobre o cinema do Irã e as estratégias estéticas de um cinema de poesia e realismo subjetivo exclusivas dos realizadores para contornar o sistema de coerção do estado islâmico.
\end{abstract}

Palavras-chave: Irã, realismo subjetivo, cinema de poesia.

\begin{abstract}
Plurality and poetic hybridization are immanent elements to the aesthetics of art cinema produced in Iran. Universal themes, self-reflexivity and the strong presence of the restriction of Islam shaped, over the years, a new way of making cinema that Persian filmmakers found for express the social reality of the country. The humanist and realist voices dialogue with the proposal of Italian Neorealism, the creative autonomy of the filmmakers refers to the innovative movement of the French Nouvelle Vague and, in some aspects, to the Third Cinema. In this article, we intend to elucidate the state's control over Iranian cinema and the aesthetic strategies of a film of poetry and subjective realism that are exclusive to filmmakers to circumvent the coercive system of the Islamic state.
\end{abstract}

Keywords: Iran, subjective realism, poetry cinema.

\footnotetext{
${ }^{1}$ Mestranda do PPGCom - UTP - Programa de Pós-Graduação em Comunicação e Linguagens da Universidade Tuiuti do Paraná, na Linha de Estudos de Cinema e Audiovisual. programacine20@gmail.com

2 PhD Univ of California, Riverside-USA; Pós-Doutora Univ do Algarve, Portugal; Docente PPGCom-UTP. denizearaujo@hotmail.com
} 


\section{Contextualização: um cinema de ambiguidades}

Liberdade; não é fácil definir este conceito. Digamos que liberdade é quando você pode escolher suas próprias ideias e pensar nelas quando quiser, sem ser forçado a pensar em outra coisa. (KHOMEINI, 1979) ${ }^{3}$

Para melhor compreendermos os processos criativos dos realizadores iranianos, analisaremos o que exatamente torna o 'Novo Cinema Iraniano' uma produção sui generis na indústria cinematográfica moderna. Desde os festivais internacionais de cinema da década de oitenta, faz-se necessário explorarmos tanto a história milenar das tradições persas, como abranger os problemas sociopolíticos enfrentados no país, nos períodos que compreendem Pré e Pós-Revolução Islâmica (1979), que fizeram das 'produções persas' um produto cultural autorreflexivo e um meio de comunicação além de um cinema autoral e esteticamente vanguardista.

Pensar o cinema iraniano exige, antes de tudo, um esforço de se desvencilhar de uma visão orientalista que configura o Oriente como um 'lugar estranho' partindo de um discurso imaginativo que se regula na "distinção ontológica e epistemológica feita entre o Oriente (a maior parte do tempo) e o Ocidente" (SAID, 1990, p.14). A ideia de Oriente implicaria em uma perspectiva delimitada por relações de interdependência organizadas sob designação acadêmica, imaginativa e como discurso regulado por uma rede de interesses vinculados à concepção colonialista, sobre a qual a cultura europeia se fortaleceu com ações de comparação, fazendo valer seu prestígio.

Conheçamos um pouco mais sobre a cultura deste país, portanto. A Pérsia passou a se chamar Irã em 1935, por uma convenção dos próprios iranianos, que não são árabes, e cuja língua é o farsi. . O islamismo foi introduzido como religião dominante com a invasão dos árabes em 633 d.C, levando ao fim a dinastia sassânida ${ }^{5}$. Anteriormente a esse período, a religião era o Zoroastrismo, crença fundada pelo profeta (e também poeta) Zaratustra

\footnotetext{
3 The New York Times Archives, outubro 1979. Reproduzido no site:

<https://www.nytimes.com/1979/10/07/archives/an-interview-with-khomeini.html, 02/07/2021>, acesso 22 de agosto de 2021

${ }^{4} \mathrm{Na}$ evolução linguística do(s) persa(s), volta a dominar o dialeto de Fârs, que se torna a forma básica do persa moderno e atual, também chamado de farsi ou dari. É esta língua - que passa a ser escrita com caracteres arábicos, incorporando um enorme léxico religioso, filosófico e científico árabe, sem, contudo, perder certa identidade - que irá plasmar a literatura persa clássica

${ }^{5}$ A dinastia sassânida governou durante o último Império Persa pré-islâmico (224-651). O Império Sassânida, que sucedeu ao Império Parta, foi reconhecido como uma das principais potências da Ásia Ocidental e Central, juntamente com o Império Romano/Bizantino, por um período de mais de 400 anos. Foi fundado por Artaxes I, após a queda do Império Arsácida e a derrota do último rei arsácida, Artabano IV. Durante sua existência, o Império Sassânida dominou os territórios dos atuais Irã, Iraque, Afeganistão, o leste da Síria, o Cáucaso (Armênia, Geórgia, Azerbaijão e Daguestão), o sudoeste da Ásia Central, parte da Turquia, certas áreas litorâneas da península Arábica, a região do golfo Pérsico, e algumas regiões do Baluquistão paquistanês. Wikipedia, agosto 2021. Reproduzido no site: <https://pt.wikipedia.org/wiki/Imp\%C3\%A9rio_Sass\%C3\%A2nida>Acesso em 03/08/2021.
} 


\section{VOZES $_{\text {\&IÁLORO }}^{\mid}$}

Itajaí, V. 20, n.02, jun-dez 2021

(558-330 a.C) que elucidaria uma fé baseada em elementos filosóficos, centralizada em uma cosmologia dualista do bem e mal, dos quais elementos teológicos influenciariam religiões póstumas como o judaísmo, cristianismo e islamismo. A Pérsia, como antes conhecida, foi a primeira superpotência da história, muito além dos suntuosos tapetes e das miniaturas bem difundidas. A vertente mística da poesia persa que mais precisamente nos interessa neste estudo está intrinsicamente ligada à pluralidade estética dos filmes iranianos.

Entrecruzando simplicidade e complexidade, documentário e ficção, o cinema persa evidencia, em suas produções, traços estilísticos que seriam equivalentes a um cinema de poesia. A confusão com os níveis de "realidade", a autorreflexividade e os frequentes 'finais em aberto' (Umberto Eco), estão profundamente ancorados aos fundamentos da poesia persa.

Se você vive num país onde uma língua de 1400 anos contém milhares de símbolos, metáforas, comparações, que, além de seus significados e interpretações místicas também sussurram conotações amorosas e sexuais, e se for alguém que desde a alvorada até o crepúsculo tem como serviço ler vigilantemente histórias e poemas procurando por símbolos e metáforas sexualmente sugestivos, então com certeza sua mente irá por instinto suspeitar de cada letra com medo de que suas conotações possam juntas cometer um pecado nas sombras da mente do leitor. (MANDANIPOUR, 2009, p.74)

O cerceamento sempre esteve presente nas manifestações artísticas do Irã, e, diferentemente da maioria dos povos, o iraniano possui uma relação substancial com a poesia desde muito cedo. Poetas que viveram há mais de mil anos são reverenciados pelo povo, que neles reconhece seu passado cultural imanente. Os poemas existem como uma marca da identidade do Irã, e possuem qualidades místicas e emocionais versificadas em expressões cotidianas. A realidade política do país não fica à parte de sua poesia. Há uma extensa lista de importantes poetas como Rumi, Hafez e Ferdowsi que demonstram não apenas as belezas e agruras da existência humana, mas também a realidade social do país.

Eu venho de um país em que os poemas são mais famosos do que pistache, caviar ou tapetes. O modo como são ditos é poético, mas não há poemas, no geral, que são bons e ao mesmo tempo apolíticos.(KIAROSTAMI, 2012, entrevista à revista Cult) ${ }^{6}$.

No Irã, poesia é também movimento e sinônimo de luta; prova disso é o fato de a Revolução Islâmica ter se iniciado em um sarau que teve duração de dez dias. Os poetas utilizaram a força de suas vozes para defender sua cultura. Com a invasão árabe, seguiram dando continuidade à preservação da língua persa em poesia oral ou escrita ${ }^{7}$ e, por meio

${ }^{6}$ Disponível no site: https://vermelho.org.br/2012/11/16/abbas-kiarostami-fala-de-seu-novo-filmeque-se-passa-no-japao. Acesso em: 23 de agosto de 2021.

7"A continuidade da língua persa após a conquista árabe da região, no século VII, é atribuída, inclusive, a um poeta do século X, Ferdowsi, que escreveu o longo poema épico Shahnameh 


\section{VOZES $_{\text {\&IÁLORO }}^{\mid}$}

Itajaí, V. 20, n.02, jun-dez 2021

de uma autêntica forma de metaforizar (com estética acurada) temas reais, o procedimento artístico milenar desdobrou-se no cinema moderno do Irã com seus realizadores.

Não obstante, a problemática da análise das hibridações poéticas no cinema iraniano consiste precisamente na dificuldade de vinculação do fator poético aos diálogos expressivos do cinema (KAHTALIAN, 2001).Portanto, a abordagem deste artigo está em estabelecer o diálogo entre 'cinema e poesia', abarcando para tanto a complexidade dos fatores envolvidos nos debates culturais e políticos do país que situam o cinema iraniano como em sua prática social, enfocando os fatores de sua pluralidade estética. Apropriamonos, portanto, dos elementos da linguagem cinematográfica para analisar a convergência das hibridações poéticas entre fato e ficção e as vozes entre a poesia e os aspectos culturais e políticos do Novo Cinema Iraniano, além de seus diálogos com o Neorrealismo Italiano, a Nouvelle Vague e o Terceiro Cinema.

\section{O cerceamento no cinema persa: vozes conservadoras $x$ reformistas}

A Revolução Iraniana (1979) pôs abaixo a monarquia autocrática do Xá Mohammad Reza Pahlevi, visto pelos revolucionários da época como um líder fascista envolvido em ações corruptas afiliadas ao Ocidente, desembocando no retorno do Aiatolá ${ }^{8}$ Ruhollah Khomeini ao Irã. Líder Supremo do país, termo criado na constituição da República Islâmica como a autoridade política e religiosa mais importante da nação, Khomeini, que havia sido exilado na França por treze anos, estabeleceu a partir daquele momento uma eficiente liderança hegemônica, que se deveu, em parte, à maioria religiosa da população.

O líder retornou à cidade de Teerã com apoio dos intelectuais, religiosos, e estado islâmico, que apoiou o governo do Aiatolá com forte repressão aos opositores, instaurando assim uma República Islâmica teocrática e arbitrariamente controlada pelos preceitos das leis religiosas. O estado islâmico usou a repressão sem restrições em sua primeira década, particularmente durante a guerra Irã-Iraque de 1980-88, que foi uma maneira de silenciar a oposição interna, enquanto os poderes coercitivos do estado continuavam a operar. No entanto, na era pós-Khomeini surgiram atritos entre a elite política, antes mantida sob o controle do líder. A elite política, gradualmente, se dividiu em duas vozes opostas, que mais tarde ficaram conhecidas como conservadoras e reformistas (ZEYDABADI, 2006).

De início, a empreitada revolucionária não trazia em seu bojo as mudanças políticas do fundamentalismo do Islã. As transformações desejadas pela população, ávida por

(Épica dos Reis) sem usar uma única palavra de origem árabe, como manifestação política contra o domínio árabe.". Disponível em: https://www.ccbraziliran.org/sobre-o-iraAcesso em 07/08/2021.

${ }^{8}$ Espelho de Deus em farsi/persa. 


\section{VOZES $_{\& \text { DIÁLORO }}^{\mid}$}

Itajaí, V. 20, n.02, jun-dez 2021

mudanças político-econômicas frente à pobreza e à inflação, não poderiam antecipar a implantação da doutrina islâmica e das tradições inventadas com a derrocada do regime do Xá. A atuação política do monarca desagradava muito por suas ações de aproximação com os Estados Unidos. A truculência da SAVAK, polícia secreta persa, que incluía em suas atuações abusos de direitos humanos e extermínio de opositores, e por fim, os movimentos de secularização da cultura islâmica contribuiriam para um 'mal estar' permanente que teve seu estopim em 1970 até chegar à revolução em 1979.

Paralelamente às opressões executadas pela corte iraniana, melhorias sociais também aconteciam. Conquistas feministas, reforma agrária e a criação do $K A N U N$ Instituto para o Desenvolvimento Intelectual da Criança e do Adolescente - que compreendia a oferta de ateliês, bibliotecas e salas de cinema para a população jovem, surgiram neste período. Desta forma, paradoxalmente, eram implantados pelo governo incentivos culturais que favoreciam a liberdade de expressão dos artistas, ainda que normatizadas pela censura. O cinema iraniano se fortalecia como 'cinema social' despontando com o surgimento de importantes realizadores persas. No entanto, a característica ideológica seguia os regimes tanto pré como pós-revolucionários:

\footnotetext{
Os governos pré e pós-revolucionários mostraram o mesmo interesse em reprimir os temas de crítica política e dissenção social, um contínuo que demonstrou como o governo dominante reconhecia o poder do cinema. Cada regime, consequentemente, tentou regular o meio de acordo com seu próprio sistema ideológico. (FARAHMAND, 2006,p.89)
}

O cinema, nesta conjuntura, era incentivado pelo $K A N U N$, bem como por outros organismos dos setores públicos e privados do Irã como a Fundação Farabi, por exemplo, com recursos financeiros e humanos, chegando a ter um departamento exclusivo para o cinema em 1966, tendo como diretor Abbas Kiarostami, importante realizador iraniano e principal agente de projeção internacional do cinema persa que influenciou a estética de outros realizadores como Jafar Panahi, Bahman Ghobadi e Ebrahim Forouzesh bastante conhecidos no cinema internacional.

No período que compreendeu os anos de 79 a 90, iniciaram-se as produções de longas-metragens pelo $K A N U N$. A estética realista despontava com maior intensidade em filmes como Khane-yeDoustKodjast? (Onde Fica a Casa do Meu Amigo?) de Abbas Kiarostami e The Cyclist (O ciclista) de MohsenMakhmalbaf, ambos produzidos em 1987. A abordagem pós-revolucionária distinguia-se da anterior (pré-revolucionária), por ser mais crua, objetiva e densamente espiritual. Exemplo disso é o filme The Houseis Black (1964) de ForoughForrokhzad, poeta e cineasta iraniana, pelo discurso cinematográfico social e autorreflexivo (mantidas as vertentes místicas da cultura persa) com símbolos e signos esteticamente pensados e traduzidos pela realidade criativa de seus realizadores.

No período pós-revolucionário, muitos artistas, ativistas políticos e cineastas foram exilados; alguns, até mesmo foram mortos por subversão à República Islâmica, fato que 


\section{VOZES $_{\text {\&IÁLORO }}^{\mid}$}

Itajaí, V. 20, n.02, jun-dez 2021

também incidia sobre o governo de Pahlevi, o então monarca e líder supremo do Irã, que por meio da $S A V A K$ impunha sua ordem ideológica.

Contudo, nada mudou nesse aspecto, com o retorno do exílio de Aiatolá Khomeini, clérigo xiita ${ }^{9}$ e líder religioso, que passou a institucionalizar o controle governamental baseado exclusivamente nas leis islâmicas para normatização da ordem pública. Dessa forma, foi intensificado o retorno das 'tradições inventadas'10 que se referiam a um passado histórico ligado ao Islã, com valores e normas de comportamentos (reais ou inventados) que estabeleciam efetivamente uma comunicação com o passado:

O governo islâmico não pode ser totalitário, nem despótico, e sim constitucional e democrático. Nessa democracia, porém, as leis não dependem da vontade do povo, mas sim unicamente do alcorão e da suma do profeta. A constituição, o código civil e código judiciário só podem se inspirar em leis islâmicas contidas no alcorão e transcritas pelo profeta, e só elas devem ser aplicadas escrupulosamente. O governo islâmico é governo de direito divino e suas leis não podem ser mudadas, modificadas nem contestadas. (KHOMEINI, 1979, p.17)

Enquanto exilado, o líder espiritual Khomeini apresentava-se com liderança populista-democrática, ocultando da opinião pública (regional e ocidental) seu posicionamento teocrático fundamentalista, da mesma maneira que também não revelara no período de exílio sua intenção de implantar o retorno das tradições inventadas, que configuraram a reconexão com este passado histórico islâmico.

Segundo Hobsbawn (2002), tradição e costume são ideias distintas, mas ambas possuem a característica da invariabilidade. Nesse sentido, o que surge depois delas deve, necessariamente, ser compatível ou idêntico ao precedente. Não impede as inovações, entretanto qualquer mudança histórica sofrerá a sanção desse mesmo precedente. Estruturados os mecanismos de controle total da nação, Khomeini parte para uma energização dos discursos de busca ao combate às imoralidades, sendo amparado

\footnotetext{
${ }^{9}$ Os principais grupos muçulmanos do Irã são xiitas e sunitas, sendo que cerca de $93 \%$ da população é xiita. Os xiitas governam o país desde o século XV; para eles somente os descendentes do profeta Maomé podem ser líderes supremos a governar o país, sendo estes representados pelos aiatolás. Desde a revolução islâmica, o Irã é uma república teocrática, cujo clero tem sua própria hierarquia. (PINTO, 2007, p. 28)

${ }^{10} \mathrm{De}$ acordo com os estudos de Alessandra Meleiro, o período que compreendeu as idealizações revolucionárias abarcava aspirações ideológicas enfocadas em um puritanismo absoluto amparado pelas leis islâmicas. Segundo a pesquisadora, com a queda do Xá Reza Pahlevi, "tradições inventadas", como as mulheres voltarem a usar véu, a não aparecer na TV e proibição de bebidas alcoólicas (para os revolucionários as verdadeiras recompensas da revolução residiam no céu) foram "resgatadas". A censura aos meios de comunicação no Irã é garantida pela constituição. O cinema tornou-se, assim, uma ferramenta de expressão dos iranianos [para] fora do país. (MELEIRO, 2006, p.20 e 34)
} 


\section{VOZES $_{\text {\&IÁLORO }}^{\mid}$}

Itajaí, V. 20, n.02, jun-dez 2021

legalmente por mudanças na constituição. Khomeini posicionara-se contra a cultura ocidental, segundo ele, responsável por injetar ideias nocivas especialmente à juventude, por meio do cinema. Para ilustrar esse efeito de invasão/imposição cultural, o religioso utilizara a palavra “rape” do inglês estupro ou violação.

Para a população iraniana, naquele momento, estabelecia-se um novo caminho na história do país, livre das influências externas com suas imposições. Com uma nova constituição, votada por ampla maioria, a República Islâmica estabeleceu-se com um sistema multipartidário, uma mistura de teocracia com democracia que não toleraria mais qualquer "opressão" de culturas desvinculadas ao Islã. Para a população, isso marcava o início de uma era independente na sua história.

O Irã não é a única república islâmica. Não é a única do mundo: há o Paquistão, a Mauritânia, por exemplo. Nem é o único país do oriente médio guiado por interpretação das leis do Islã. Mas é o único no qual o clérigo comanda oficialmente, diferente de determinados vizinhos onde a presença da religião também é muito forte, e que vivem sob sistemas monárquicos. (KALILI, SARTORI, 2004, p.22)

A ideia que se estabelecia na população iraniana, portanto, era a de que, a partir daquele momento histórico, o Irã seria um país totalmente autônomo em termos de leis e de conceituações ideológicas, livre das influências ocidentais para tanto. Porém, o que de fato ocorreu com esse adensamento do regime islâmico foi uma reordenação política e social que restringiu parte dos avanços intelectuais e tecnológicos da sociedade, baseados em um patriotismo inventado: "essas práticas que simbolizam o patriotismo nada mais são do que práticas inventadas que tendem a ser bastante gerais e vagas quanto à natureza dos valores, direitos e obrigações, mas que procuram inculcar nos membros da sociedade conteúdos mal definidos como "lealdade" e "dever" (MELEIRO, 2006, p. 38).

Com o adensamento do regime, os cineastas tiveram que buscar meios de se adaptar aos novos códigos da censura, fato que exigia uma reflexão ainda maior sobre a natureza de seus trabalhos. O período obscuro fortaleceu o viés ideológico e as temáticas próprias do cinema persa. Os movimentos anti Xá e anti-Ocidente permaneceram nas produções voltadas ao consumo interno, reforçando o domínio do clérigo com filmes de propaganda que exaltavam o regime.

Durante a guerra Irã-Iraque, temáticas nacionalistas no cinema visavam reforçar a islamização da sociedade. Neste ínterim, o 'cinema de arte', enfocado no mercado internacional, aliava-se aos movimentos de reorganização da indústria cinematográfica, se sobressaindo como cinema de cunho político e autocrítico.

Podemos dizer, portanto, que coexistem 'dois nichos' no cinema iraniano: o primeiro, com objetivo de venda e exibição de filmes para a população iraniana, comprometido com a propaganda do governo, e o segundo, que vem a ser o cinema de 


\section{VOZES $_{\text {\&IÁLORO }}^{\mid}$}

Itajaí, V. 20, n.02, jun-dez 2021

arte, enfocado nas projeções internacionais e na reflexividade das temáticas que compõem a realidade social do país.

De fato, dois tipos de cinema têm se desenvolvido lado a lado. O "cinema popular" que afirma os valores pós revolucionários islâmicos, a nível de trama, tema, caracterização, retrato da mulher e mise-enscène. O cinema de arte, por outro lado, se compromete com esses valores e tende a criticar condições sociais sob o governo islâmico. (NAFICY, 2006, p. 30)

Na medida em que o regime estreitava as regulamentações para criação de roteiro e exibição dos filmes, a escolha pelos filmes protagonizados por crianças acabou sendo um recurso de dilatação das restrições para filmagens, especialmente nos filmes de arte.

O controle exercido pelo Estado manteve (e mantém) o intervencionismo coercitivo do MCOI (Ministério da Cultura e Orientação Islâmica, antes apenas Ministério da Cultura), sobre todas as produções cinematográficas com regulamentações para exibição, exportação e venda das películas.

\section{Diálogos com Neorrealismo Italiano, Nouvelle Vague e Terceiro Cinema}

A milenar estratégia de 'comunicação indireta', utilizada pelos místicos iranianos para comunicar pensamentos e crenças manteve-se no cinema pelos realizadores. Longas como 'O Jarro’ (1992), de Ebrahim Forouzesh, ‘O Balão Branco’ (1995), de Jafar Panahi, 'O Silêncio', (1998) de MohsenMakhmalbaf e 'Filhos do Paraíso' (1999), de MajidMajidi, são filmes representados por crianças que, pelo simbolismo das temáticas infantis, contornaram as restrições dos censores.

As películas possuíam em estoque significados muito variados e sutis. Com temáticas sensíveis, desdobradas em vozes e imagens, a naturalidade da representação pueril captada pela objetiva quase documental do cinema iraniano seria equivalente a uma 'limpeza do olhar' do espectador ocidental. Os filmes eram sobre crianças (mas não para elas) e marcaram o período pós-Revolução, em que "a construção de significados envolvia os censores, os cineastas e o público” (ZEYDABADI, 2006, p.28).

\footnotetext{
No início dos anos 1990, esse cinema surpreendia o Ocidente, formulando por intermédio de protagonistas infantis uma outra percepção possível para o mundo islâmico - a pureza e a plasticidade da criança permitiam evocar outras formas de imaginário para o Irã. (FRANÇA, 2006 p. 406)
}

Deste modo, os realizadores elaboravam um discurso cinematográfico alusivo às questões sociais permanentes da República Islâmica e, a partir de uma abordagem estética 


\title{
VOZES $_{\text {\&IÁLORO }}^{\mid}$
}

Itajaí, V. 20, n.02, jun-dez 2021

e de um recorte criativo da realidade, as vozes estilísticas marcantes deste cinema funcionariam como agentes mediadores de certa realidade subjetiva. Por meio de uma linguagem simbólica, os verdadeiros aspectos autorreflexivos da diegese ficavam latentes na sugestão dos realizadores, produzindo o efeito contrário da seguinte citação: “... creio que muitos filmes mostram demais e, dessa maneira, perdem o efeito" (KIAROSTAMI, 2004, p.54). A poética imanente ao cinema iraniano emerge, portanto, das lacunas e ambiguidades que colocam de lado o melodrama, e escapam à estética narrativa lógicocausal.

O crescimento de produções protagonizadas por crianças na primeira década após a revolução e o aperfeiçoamento da estética dos filmes no decorrer dos anos imbricaram em um cinema de vozes ambíguas: a voz da arte e voz da criatividade que dialogam com vozes críticas e de resistência, o que contempla o Neorrealismo Italiano dos anos 1940. As frequentes temáticas do cotidiano somadas à representação de um universo cultural desconhecido para a maioria dos espectadores interagiram na manifestação de um estilo novo que funcionaria como uma descoberta de um novo olhar para o cinema.

A vida cotidiana era a temática basilar dos cineastas neorrealistas, um estilo seguido pelos realizadores iranianos, que criaram, como seus antecessores da Nouvelle Vague, experimentalismos poéticos em imagens e roteiros que refletem as ambiguidades de suas produções. Se por um lado o Novo Cinema Iraniano poderia ser designado de neorrealista considerando seus temas, por outro lado poderia ser outra versão da Nouvelle Vague se considerarmos as experimentações de seus realizadores. Além disso, para alguns pesquisadores, o cinema iraniano pertence ao conceito de Terceiro Cinema, surgido na América Latina com importantes realizadores vinculados à militância no cinema político.

Em relação ao neorrealismo, a utilização de não atores, tomadas mais longas, uso de iluminação natural e linguagem metafórica tensionam a vertente humanista que desemboca em um cinema que contempla uma "impressão de verdade":

\begin{abstract}
A profissão não é apenas uma contraindicação, ao contrário, mas ela se reduz a uma agilidade útil que ajuda o ator obedecer às exigências da mise-en-scène e a penetrar melhor em seu personagem. Os não profissionais são naturalmente escolhidos por sua adequação ao papel que devem desempenhar: conformidade física ou biográfica. Quando o amalgama tem êxito - a experiência mostra, porém, que isso só pode acontecer se certas condições de certo modo "morais" do roteiro forem reunidas- obtemos, precisamente, essa extraordinária impressão de verdade nos filmes italianos atuais. (BAZIN, 1991, p. 240-241)
\end{abstract}

Assim como na estética neorrealista os atores eram não profissionais, no cinema iraniano os limites impostos pelas restrições de filmagem impulsionaram as representações da imagem do povo nas telas, e para isso, nada melhor do que se selecionar pessoas comuns e crianças. No que tangencia ao caso específico do cerceamento, a atuação do cinema do 


\section{VOZES $_{\text {\&IÁLORO }}^{\mid}$}

Itajaí, V. 20, n.02, jun-dez 2021

Irã escapa à rigidez da dualidade com oposições demasiadamente imutáveis, uma vez que cineastas com visão crítica, em algumas situações, foram ajudados por autoridades reformistas, ainda que limitados em outros momentos por seus oponentes conservadores. Os realizadores, nesse ínterim, encontraram, nos moldes da Nouvelle Vague, referências estéticas que permitiram uma maior autenticidade a suas experimentações e às estratégias que colocam a naturalidade da performance como condutora das cenas, implicitando suas vozes e ideologias em uma segunda camada percebida por espectadores com repertórios.

A vinculação ao ThirdCinema, no caso iraniano, flui de sua dimensão cultural que se dispõe em uma concepção da imagem enfocada também na "descolonização da cultura" (SOLANAS e GETINO,1969). As alegorias ao contexto social, factualmente mais amplo, dinamizadas nos frequentes planos-sequência, locações realistas e predileção pelos nãoatores funcionam como mecanismos estilísticos de redução do efeito hegemônico. Em vista disso, caracteriza-se na recusa da estética comum com representações autênticas e uma proposta antiimperialista, confrontando os sistemas da linguagem cinematográfica clássica e a predominância de imagens estereotipadas.

Ao tencionar o determinante ideológico, podemos encontrar no 'Novo Cinema Iraniano’ (pós-revolução) algumas práticas comuns às do Terceiro Cinema: a forte politização temática, o deliberado discurso dos realizadores contra sistemas de opressão, as representações anticapitalistas com locações modestas e utilização de não-atores. Entretanto, há uma disparidade que insurge dos limites da própria cultura persa e que não podemos cotejar com nenhuma outra. Por conseguinte, torna-se impreciso categorizar integralmente o cinema persa como parte deste movimento.A presença do cerceamento do Islã sobrepõe às estratégias dos cineastas um modus operandi que não pode ser comparado a outras produções cinematográficas do Terceiro Cinema, considerando que o caso desta censura se estabelece no amálgama da tríade indissociável: islã-políticamanifestações artísticas.

Portanto, a associação do cinema persa com o Terceiro Cinema, restringe-se à faceta mais idealista e de cunho libertário deste movimento, seguindo o fluxo da reorganização cultural das artes cinematográficas:

O "mundo" viu Cuba, as guerrilhas, Che, a Revolução Cultural Chinesa: A cultura mundial acabou sendo influenciada e influenciando os movimentos políticos simultaneamente. Ou seja, o conceito de TerceiroMundo serve a partir dos anos 60 - para além das delimitações eufemísticas e conservadoras da geografia contemporânea - para estabelecer uma unidade de cunho libertário e idealista. Os processos de descolonização, de conscientização social e de luta política desencadeados no globo ao longo deste período não se esgotam em si mesmos: eles fazem parte da grande crise da modernidade que implica também numa reorganização (ou desorganização) cultural em todos os cantos do globo. Uma das mais diretas e evidentes influências da consciência terceiro-mundista (e todas as suas implicações) foi a própria constituição da ideia de Terceiro Cinema (PRYSTHON, 2006, p. 9) 


\section{VOZES $_{\text {\&IÁLORO }}^{\mid}$}

Itajaí, V. 20, n.02, jun-dez 2021

Os cineastas iranianos ligados à vertente do cinema de arte aderiram à identidade contra hegemônica do Terceiro Cinema, expondo desse modo as múltiplas camadas do cinema persa, com divisões e estratificações que se opunham gradualmente entre o cinema projetado para os festivais e o cinema como mecanismo da islamização da cultura, "aquilo que se referem como censura no Irã deve ser considerado como restrições religiosas”(Iran, a cinematographicrevolution, 2006)11frase dita pelo cineasta Abbas Kiarostami que direciona nossos olhares para a singularidade política e estética do cinema persa como expressão única e isolada.

Considerações Finais

Apesar de vozes que dialogam com o Neorrealismo Italiano, com a Nouvelle Vague e, em certos aspectos, com o Terceiro Cinema, o Novo Cinema Iraniano distingue-se desses outros cinemas pela inauguração de uma estética que se faz na poesia e na autorreflexividade. Sua proposta desvela uma autenticidade exclusiva de seus realizadores por eventos realistas e do cotidiano, estabelecendo assim um metarrealismo ainda em campo de estudos sobre sua natureza peculiar.

No filme Close-Up (1999), de Abbas Kiarostami, vencedor da Palma de Ouro em Cannes, um jovem tipógrafo desempregado chamado HossainSabzian, ao apanhar um microônibus e se sentar ao lado da senhora Ahanjah, se passa pelo cineasta MohsenMakhmalbaf. Ele tem acesso à sua família e passa a iludi-los sobre a suposta gravação de um filme que os envolveria. Tardiamente, a família da senhora descobre que o verdadeiro Makhmalbaf estava recebendo um prêmio na Itália de melhor filme por $O$ Ciclista, no Rimini Festival. O diretor impostor é então denunciado às autoridades, e revela que o seu amor pelo cinema destruiu a sua vida. O roteiro do filme foi desenvolvido a partir da leitura de Kiarostami sobre o artigo da Revista Soroush, que relatava todo o caso de Sabzian: "Eu tinha uma equipe para fazer outro filme. Então, três dias antes da filmagem, me deparei com uma notícia em uma revista que me tirou o sono, pois me sentia muito próximo deste assunto.

O metarrealismo que se inscreve nessa ambiguidade se dá entre o fato ocorrido e a mise- en- scène.De um lado temos uma situação real que envolve uma notícia de jornal e revista, e do outro um "recorte criativo dessa realidade, filtrada pelo ponto de vista do cineasta sobre seu mundo histórico" (NICHOLS, 2005), nesse caso, poetizada pelas lentes de Kiarostami.

A vocação documental-realista do cinema iraniano, muito pertinente à teoria baziniana no tocante à representação da opacidade na tela, corporifica o hibridismo da tensão do eixo ficção/documentário. Tanto na forma como no conteúdo, as películas

\footnotetext{
"IRAN - A CINEMATOGRAPHIC REVOLUTION. Direção: Nader TakmilHomayoun. Irã: 2006, DVD (98 $\mathrm{min})$
} 


\section{VOZES $_{\text {\&IÁLORO }}^{\mid}$}

Itajaí, V. 20, n.02, jun-dez 2021

persas acendem à hipótese da presença de um novo realismo no cenário cinematográfico mundial; as temáticas do cotidiano surpreendem pela sensibilidade dotada de dados senão naturais da imagem, muito próximos de um recorte da vida comum, tal qual ela é. Por este ângulo, à revelia dos padrões clássicos e bem distante da relação causa e efeito, essas produções engendram, por seus materiais expressivos, um novo discurso que se institui numa realidade desdobrada em si mesma, ou seja, uma realidade que se instaura por sua autorreflexividade, expressando assim um realismo subjetivo e intencional.

Um outro exemplo de filme com estética metarrealista é $O$ Espelho (1997) de Jafar Panahi. O diretor desvela uma construção social ausente de ilusionismo, e o que seria um filme passa a se apresentar em certo momento da narrativa como documentário, mostrando as câmeras e a desistência da pequena protagonista em participar das filmagens: "o espectador torna-se um observador e consegue ver o cinema como linguagem, como discurso, todo seu processo de identificação que envolve suas emoções e que poderia levar à catarse se rompe e ele passa a olhar com certa distância para as imagens que se tornaram opacas” (PESSUTO, 2011, p.62).

A gravação continua e o diretor, câmeras, figurantes e operador de som aparecem nos planos a partir daí, e passam a interagir com Mina, que segue rumo à sua casa, talvez não mais como atriz, e sim como uma menina que precisa chegar à sua casa. Nuances da metalinguística, planos-sequência mais longos, atuação de não atores e a contínua função social das locações são tanto escolhas econômicas quanto estéticas dos diretores que permitem de fato uma maior autenticidade.

O Novo Cinema Iraniano emblematiza a poética do realismo subjetivo, envolto em recortes do real e do cotidiano que oferecem maiores possibilidades e tempo à audiência. As lacunas precisam ser preenchidas pela capacidade criativa de seus espectadores, da qual reverberarão muitas vozes, vozes estas provenientes das interpretações dos silêncios sempre abundantes e das metáforas e elipses da diegese. Suas múltiplas camadas de significados coadunam mistério e evidência, estratégias de artistas milenares da cultura persa, na poesia e no cinema.

\section{Referências}

BAZIN, A. O Cinema - Ensaios. São Paulo: Brasiliense, 1991.

ECO, U. Obra Aberta: forma e indeterminação nas poéticas contemporâneas. São Paulo: Perspectiva, 1993.

FARAHMAND, A. Perspectives onrecent (internationalacclaim for) Iranian Cinema. In: TAPPER, R. (Ed.). The New Iranian Cinema. New York: I. B. Tauris, 2006. p. 86-108.

FRANÇA, A. MASCARELLO, F. (org.). História do Cinema Mundial. Campinas: Papirus, 2008. 
GETINO, O; SOLANAS, F. (1969). Toward a Third Cinema. disponível em: $<$ https://ufsinfronteradotcom.files.wordpress.com/2011/05/tercer-cinegetino-solonas19691.pdf> Acesso 17/08/202.

HOBSBAWN, E.; RANGER, T. A Invenção das tradições. São Paulo: Paz e Terra, 2002.

IRAN - A CINEMATOGRAPHIC REVOLUTION. Direção: Nader TakmilHomayoun. Irã: 2006, DVD (98 min)

KAHTALIAN, M. O cinema fundamentalista: o cinema iraniano após a revolução islâmica. Dissertação de mestrado apresentada na UNICAMP, 2001.

KALILI, S.; SARTORI, A. A revolução ameaçada. Reportagem, São Paulo, n. 53, fev., 2004 .

KHOMEINI, A. Livro verde dos princípios políticos, filosóficos, sociais e religiosos do Aiatolá Khomeini. Rio de Janeiro: Record, 1979.

KIAROSTAMI, A. Abbas Kiarostami: duas ou três coisas que sei sobre mim. São Paulo: Cosac Naify, 2004.

MANDANIPOUR, S. Quando o Irã censura uma história de amor. Rio de Janeiro:Record, 2009.

MELEIRO, A. O Novo Cinema Iraniano: arte e intervenção social. São Paulo: Escrituras, 2006.

NAFICY, H. Islamizingfilmculture in Iran: a post-Khatami update. In: TAPPER, R. (Ed.). The New Iranian Cinema. New York: I. B. Tauris, 2006. p. 26-65

NICHOLS, B. Introdução ao documentário. Campinas: Papirus Editora, 2007.

PESSUTO, K. O 'espelho mágico' do cinema iraniano: uma análise das performances dos "não" atores nos filmes de arte. Dissertação (Mestrado em Artes) Instituto de Artes, Universidade Estadual de Campinas. 2011.

PINTO, I. M. “Close-up - a Invenção Do Real Em Abbas Kiarostami.” www.teses.usp.br, 11 setembro 2007. <www.teses.usp.br/teses/disponiveis/27/27153/tde05072009-203915/pt-br.php> Acesso agosto 2021. 


\section{VOZES $_{\& \text { DIÁLORO }}^{\mid}$}

Itajaí, V. 20, n.02, jun-dez 2021

PRYSTHON, A. Imagens periféricas: os Estudos Culturais e o Terceiro Cinema. Revista da Associação Nacional dos Programas de Pós-Graduação em Comunicação. Universidade Federal de Pernambuco. Disponível em:<http://www.compos.com.br/ecompos>

Record, 2009. Acesso em: 04/09/2021.

SAID. E. W. Orientalismo: o Oriente como invenção do Ocidente /Edward W. Said; tradução Tomás Rosa Bueno. - São Paulo: Companhia das Letras, 1990.

ZEYDABADI-N. S. The politicsofIranian cinema: filmand society in theIslamicRepublic / Basedontheauthor'sthesis (doctoral) - Schoolof Oriental and African Studies, 2006.

\section{Filmografia}

The House is Black. Direção: Forugh Farrokhzad. Irã: 1964, DVD (20 min).

O Balão Branco. Direção: Jafar Panahi. Irã: 1995, DVD (85 min).

Onde Fica A Casa Do Meu Amigo? Direção: Abbas Kiarostami. Irã: 1987, DVD (83 min).

3 Faces. Direção: Jafar Panahi. Irã:2018, DVD (1h40m)

O Ciclista. Direção: Mohsen Makhmalbaf. Irã:1987, (1h35m)

OJarro. Direção: Ebrahim Forouzesh. Irã: 1992, (90m)

O Silêncio. Direção: Mohsen Makhmalbaf. Irã:1998, (1h16m)

Filhos Do Paraíso. Direção: Majid Majidi. Irã:1997, (1h29m)

Close-Up: Direção: Abbas Kiarostami. Irã: 1990, DVD (1h38m)

O Espelho: Jafar Panahi. Irã: 1997, DVD (1h35m) 